\title{
Precise pretreatment of lignocellulose: relating substrate modification with subsequent hydrolysis and fermentation to products and by-products
}

Fan Lü ${ }^{1}$, Lina Chai ${ }^{1}$, Liming Shao ${ }^{2}$ and Pinjing $\mathrm{He}^{2,3^{*}}$ (D)

\begin{abstract}
Background: Pretreatment is a crucial step for valorization of lignocellulosic biomass into valuable products such as $\mathrm{H}_{2}$, ethanol, acids, and methane. As pretreatment can change several decisive factors concurrently, it is difficult to predict its effectiveness. Furthermore, the effectiveness of pretreatments is usually assessed by enzymatic digestibility or merely according to the yield of the target fermentation products. The present study proposed the concept of "precise pretreatment," distinguished the major decisive factors of lignocellulosic materials by precise pretreatment, and evaluated the complete profile of all fermentation products and by-products. In brief, hemicellulose and lignin were selectively removed from dewaxed rice straw, and the cellulose was further modified to alter the crystalline allomorphs. The subsequent fermentation performance of the selectively pretreated lignocellulose was assessed using the cellulolytic, ethanologenic, and hydrogenetic Clostridium thermocellum through a holistic characterization of the liquid, solid, and gaseous products and residues.
\end{abstract}

Results: The transformation of crystalline cellulose forms from I to $I$ and from $I_{\alpha}$ to $I_{\beta}$ improved the production of $\mathrm{H}_{2}$ and ethanol by 65 and 29\%, respectively. At the same time, the hydrolysis efficiency was merely improved by 10\%, revealing that the crystalline forms not only influenced the accessibility of cellulose but also affected the metabolic preferences and flux of the system. The fermentation efficiency was independent of the specific surface area and degree of polymerization. Furthermore, the pretreatments resulted in $43-45 \%$ of the carbon in the liquid hydrolysates unexplainable by forming ethanol and acetate products. A tandem pretreatment with peracetic acid and alkali improved ethanol production by $45.5 \%$, but also increased the production of non-ethanolic low-value by-products by $136 \%$, resulting in a huge burden on wastewater treatment requirements.

Conclusion: Cellulose allomorphs significantly affected fermentation metabolic pathway, except for hydrolysis efficiency. Furthermore, with the increasing effectiveness of the pretreatment for ethanol production, more nonethanolic low-value by-products or contaminants were produced, intensifying environmental burden. Therefore, the effectiveness of the pretreatment should not only be determined on the basis of energy auditing and inhibitors generated, but should also be assessed in terms of the environmental benefits of the whole integrated system from a holistic view.

Keywords: Lignocellulose, Precise pretreatment, Selective pretreatment, Environmental assessment, Crystalline form, Holistic view

\footnotetext{
${ }^{*}$ Correspondence: solidwaste@tongji.edu.cn

${ }^{2}$ Institute of Waste Treatment and Reclamation, Tongji University,

Shanghai 200092, China

Full list of author information is available at the end of the article
} 


\section{Background}

Lignocellulosic biomass is an important renewable resource for the bioproduction of ethanol, $\mathrm{H}_{2}$, or organic acids [1, 2]. Numerous studies have established the importance of delignification, depolymerization, and decrystallization by various pretreatments [3-9]. The contents of lignin and hemicellulose, the degrees of crystallinity and polymerization, and the accessibility of the cellulose are regarded as the decisive factors affecting the effectiveness of pretreatments [10-14]. Since a pretreatment can change the above-mentioned parameters concurrently, the exact mechanism(s) underlying the effectiveness of diverse pretreatment strategies under different reaction conditions on diverse lignocellulosic materials are not conclusively known $[3,10,12,15]$.

Meanwhile, the effectiveness of pretreatments is invariably assessed by enzymatic hydrolysis or digestibility [11, 16-21], or according to the yield of the target fermentation products (mainly ethanol) [22]. Higher digestibility is preferred, while the fate of hydrolysates or non-target fermentation products from the pretreated biomass is seldom considered. Factors such as whether or not and how pretreatments affect a subsequent microbial fermentation are seldom discussed or included with the several potential mechanisms. If hydrolysis is increased and fermentation is decreased by pretreatment, the reduced fermentation efficiency is often attributed to the formation of inhibitory by-products during pretreatment [6].

Accordingly, the possibility of a precise pretreatment on lignocellulose is then speculated. Precise pretreatment is defined as the pretreatment measures that are carefully selected, optimized, combined, and customized, precisely according to the modification mechanism of each measure and the potential effect on the subsequent productoriented utilization; the potential effect of each measure is fully expectable and controllable.

In targeting the question of how pretreatment of lignocelluloses affects the subsequent fermentation performance, in the present study the hemicellulose or lignin was selectively removed from the lignocellulose, and the crystalline allomorph of the cellulose was further modified. The selectively pretreated lignocelluloses were subjected to fermentation by anaerobic Clostridium thermocellum, realizing simultaneous solid-state saccharification and production of ethanol, $\mathrm{H}_{2}$, and acids. A holistic characterization of the pretreated substrates and the liquid, solid, and gaseous products and residues was conducted, aiming at comprehensively revealing the efficiency through precise pretreatment.

\section{Methods}

Raw materials and anaerobic microorganism

Fresh rice straw was sequentially washed with distilled water, air-dried, dewaxed with toluene/ethanol (2:1, v/v) at $150{ }^{\circ} \mathrm{C}$ for $6 \mathrm{~h}$ in an auto-Soxhlet apparatus (Soxtec ${ }^{\mathrm{TM}}$ 2050, FOSS, Denmark), washed with ethanol until the residual toluene was thoroughly removed, and then dried at $35{ }^{\circ} \mathrm{C}$ in an oven to constant weight. The dewaxed rice straw sample was denoted as "S."

The thermophilic anaerobic cellulolytic C. thermocellum strain DSM 2360 was obtained from DSMZ (Deutsche Sammlung von Mikroorganismen und Zellkulturen, Germany) and cultivated as described previously [23, 24].

\section{Pretreatment measures}

Three types of pretreatment were applied to the rice straw prepared as described above. (1) Dilute acid pretreatment was used to remove hemicellulose and increase the porosity (sample denoted as "DS"): the dewaxed straw was mixed with $1.5 \%(\mathrm{w} / \mathrm{v})$ dilute sulfuric acid at a solid-to-liquid ratio of $2.5 \%(\mathrm{w} / \mathrm{v})$ at $121{ }^{\circ} \mathrm{C}$ for $1 \mathrm{~h}$. (2) Peracetic acid (PAA) pretreatment was used to remove lignin (sample denoted as "PS"): the dewaxed straw was mixed with PAA at a solid-to-liquid ratio of 1:10 (w/v) at $80{ }^{\circ} \mathrm{C}$ for 2 or $3 \mathrm{~h}$ (samples denoted as "PS2" and "PS3," respectively). (3) Tandem PAA- $\mathrm{NaOH}$ pretreatment was used to remove lignin and modify the cellulose (sample denoted as "NS"): the above PAA-pretreated ( $2 \mathrm{~h}$ ) straw was mercerized by $12.5 \%(\mathrm{w} / \mathrm{v}) \mathrm{NaOH}$ at a solid-to-liquid ratio of $1: 20(\mathrm{w} / \mathrm{v})$ at $30^{\circ} \mathrm{C}$ for $1.5 \mathrm{~h}$. The pretreated rice straw samples were washed thoroughly with hot distilled water until the eluate was $\mathrm{pH}$ neutral, and then dried at $35^{\circ} \mathrm{C}$ to constant weight.

\section{Anaerobic fermentation of rice straw}

The pretreated and untreated rice straw samples served as substrates for $C$. thermocellum. The incubation was conducted in triplicate at $55 \pm 2{ }^{\circ} \mathrm{C}$ in a 250 - $\mathrm{mL}$ serum bottle containing $1.5 \mathrm{~g}$ rice straw, $150 \mathrm{~mL}$ cultivation medium, and $7.5 \mathrm{~mL}$ of freshly harvested C. thermocellum, and sparged with $\mathrm{N}_{2}$ to obtain anaerobic status. Meanwhile, a blank without substrate that only contained C. thermocellum broth was used as the control. During the incubation, on the 461st $\mathrm{h}$, the $\mathrm{pH}$ value of all the batches was regulated to 7.2 with the addition of $\mathrm{NaOH}$ and $\mathrm{HCl}$ solutions under anaerobic condition.

Liquid samples were collected periodically during each run, under anaerobic conditions, and the $\mathrm{pH}$, volatile fatty acids, alcohols, and dissolved organic carbon (DOC) were measured. The production of gaseous $\mathrm{H}_{2}$ was calculated by determining the pressure and composition of the gas in the headspace.

\section{Analysis of liquid and gaseous metabolites from anaerobic fermentation}

The $\mathrm{pH}$ was measured immediately after liquid sampling using a $\mathrm{pH}$ meter (pHS-2F, Shanghai Precision and 
Scientific Instrument Co. Ltd. China). After centrifugation at $16,000 \times g$ for $10 \mathrm{~min}$, the contents of alcohols (including methanol, ethanol, $n$-propanol, $i$-propanol, $n$-butanol) and acids (including acetic, propionic, $n$-butyric, isobutyric, isovaleric, and $n$-valeric acids) in the supernatants of the liquid samples were determined by gas chromatography (6890N-FID, Agilent, USA) using a system equipped with a DB-WAXETR1 capillary column $(30 \mathrm{~m} \times 0.53 \mathrm{~mm}$ i.d. $\times 1 \mu \mathrm{m})$ according to the protocol described previously [24]. The DOC of the metabolites was detected using a total organic carbon analyzer (TOC V-CPN, Shimadzu, Japan). The gaseous composition $\left(\mathrm{H}_{2}, \mathrm{CO}_{2}, \mathrm{CH}_{4}, \mathrm{~N}_{2}, \mathrm{O}_{2}\right)$ and pressure were detected by gas chromatography (GC9800, Shanghai Precision and Scientific Instrument Co. Ltd. China) and using a pressure meter (TESTO 512, Barometer, Germany), respectively.

\section{Biochemical components and functional groups of the fibers}

The cellulose, hemicellulose, and lignin contents in the fiber samples were determined by sequentially extracting the neutral detergent fiber, acid detergent fiber, lignin, and ash, according to the modified method proposed previously $[25,26]$. The sequential extraction was conducted in a crude fiber extractor (FiberCap ${ }^{\mathrm{TM}}$ 2021, FOSS, Denmark).

The functional groups on the surface of the fibers were detected using an X-ray photoelectron spectrometer (XPS, PHI 5000C ESCA). The area illuminated by the irradiation was $<1 \mathrm{~mm}$ in diameter. XPS wide scans at 0-1100 eV and C1s core-level spectra were recorded with the steps of 1.0 and $0.15 \mathrm{eV}$, respectively.

\section{Crystallinity and crystal forms of cellulose in the fibers}

The crystallinity and crystal forms of the cellulose were characterized by solid-state cross-polarization/magic angle spinning (CP/MAS) ${ }^{13} \mathrm{C}$ NMR. Cellulose was isolated according to the following protocol, as modified from a previous procedure [26]; Briefly, the fiber samples $(9 \mathrm{~g})$ were dispersed into $750 \mathrm{~mL}$ of deionized water. Then glacial acetic acid $(6 \mathrm{~mL})$ and sodium chlorite $(6 \mathrm{~g})$ were added to the mixture. The mixture was sealed in a reaction flask and maintained at $70{ }^{\circ} \mathrm{C}$ with stirring for $2 \mathrm{~h}$. This treatment was repeated until the solid residue turned white and the lignin content was very low. After that, cellulose was isolated from $2 \mathrm{~g}$ of solid residue by soaking in $200 \mathrm{~mL}$ of $2.5 \mathrm{M} \mathrm{HCl}$ at $100{ }^{\circ} \mathrm{C}$ for $4 \mathrm{~h}$ and was then filtered and washed with deionized water.

Solid-state NMR measurements were carried out on a AVANCE III 400 WB spectrometer (Bruker, Germany) operating at a frequency of $100.69 \mathrm{MHz}$ for ${ }^{13} \mathrm{C}$ using a 4-mm Bruker double-resonance MAS probe head at a spinning speed of $10 \mathrm{kHz}$. Acquisition was performed with a $\mathrm{CP}$ pulse sequence using a $2.5-\mu$ s proton $90^{\circ}$ pulse, a 1.5-ms contact pulse, and a 3.0-s delay between repetitions.

\section{Degree of polymerization of cellulose in the fibers}

The number-average molecular weight $\left(\bar{M}_{\mathrm{n}}\right)$ and the weight-average molecular weight $\left(\bar{M}_{\mathrm{w}}\right)$ were determined by gel permeation chromatography after tricarbanilation of the cellulose according to a previously described procedure [27]. Gel permeation chromatography (Waters 515, Milford, MA, USA) equipped with three columns, Styragel HR3, HR4, and HR5, and a refractive index detector was run at a column temperature of $35^{\circ} \mathrm{C}$ and a flow rate of $1 \mathrm{mg} / \mathrm{mL}$. The weight-average degree of polymerization $\left(\mathrm{DP}_{\mathrm{w}}\right)$ and the number-average degree of polymerization $\left(\mathrm{DP}_{\mathrm{n}}\right)$ were obtained by dividing $\bar{M}_{\mathrm{w}}$ and $\bar{M}_{\text {n }}$, respectively, by $519 \mathrm{~g} / \mathrm{mol}$, i.e., the molecular weight of the cellulose tricarbanilate monomer.

\section{Specific surface area and micro-morphological structure}

The specific surface area of the fibers was determined by Brunauer, Emmett, and Teller (BET) nitrogen adsorption-desorption isotherms at $-195{ }^{\circ} \mathrm{C}$ in a surface area analyzer (ASAP 2020 V3.04H, Micromeritics Co. Norcross, GA, USA). Prior to determination, the sample was degassed for $3 \mathrm{~h}$ at $80{ }^{\circ} \mathrm{C}$ under vacuum $\left(P / P_{0}=0.25\right)$ to remove moisture and any other contaminants.

The surface micro-morphological structures of the exterior and interior surfaces of the samples were examined by scanning electron microscopy (SEM, S-3400 N, Hitachi Ltd. Tokyo, Japan) at a voltage of $15 \mathrm{kV}$. Specimens were prepared for SEM inspection by placing the samples on carbon glue and then plating them with Pt $(7 \mathrm{~nm})$. Ultrathin sections of fibers were utilized to observe the changes in cell walls detected by transmission electron microscopy (TEM) and atomic force microscopy (AFM). TEM was conducted on a JEM-2100 microscope (JEOL, Tokyo, Japan). AFM was conducted on a Dimension 3100 microscope (Veeco Instruments Inc. Plainview, NY, USA). Images were captured using silicone cantilevers. The scanning rate ranged from 0.5 to $1.5 \mathrm{~Hz}$.

\section{In situ visualization of cellulose accessibility to cellulase}

The accessibility of the cellulose to cellulase was detected by Trx-Green Fluorescent Protein-CtCBM3 (TGC) labeling and observed by confocal laser scanning microscopy (Leica TCS SP5II, Leica, Mannheim, Germany) under $63 \times 10$ magnification. The details of TGC labeling were described previously [23], where bovine serum albumin (BSA) protein was used to block the lignin. A 488-nm argon laser was used for excitation. The emission bandwidth was set between 500 and $550 \mathrm{~nm}$ for collection 
of the TGC fluorescence. Images were obtained within a $30-\mu \mathrm{m} z$-depth containing eight confocal planes and obtained at a resolution of $1024 \times 1024$ pixels.

\section{Results}

\section{Metabolite recovery via anaerobic fermentation}

Figure 1 clearly indicates that pretreatment altered the hydrolysis and acidogenesis efficiency of the straw. It is noted that the values of DOC, ethanol, acetic acid, and $\mathrm{H}_{2}$ of the control batch were subtracted from those of the experimental samples. The maximal DOC yields of the straw substrates were $179 \pm 8,159 \pm 5,315 \pm 23$, $337 \pm 5$, and $368 \pm 14 \mathrm{~g}$-C/g-DW (Note: DW means a dry weight basis), or $238 \pm 11,213 \pm 7,409 \pm 29$, $404 \pm 6$, and $411 \pm 16 \mathrm{~g}$-C/g-holocellulose on the basis of summing cellulose and hemicellulose, for S, DS, PS2, PS3, and NS samples, respectively. Therefore, the hydrolysis efficiency of the straw did not improve upon dilute sulfuric acid pretreatment, whereas it was increased by $76-88 \%$ on a dry weight basis with PAA pretreatment and further increased by $106 \%$ with a combination of PAA and alkali pretreatment.

However, the ultimate yields of acidogenesis metabolites were improved to a lesser extent. In fact, dilute sulfuric acid pretreatment decreased the ultimate yields of $\mathrm{H}_{2}$, ethanol, and acetic acid by $31.0,0.5$, and $37.4 \%$,
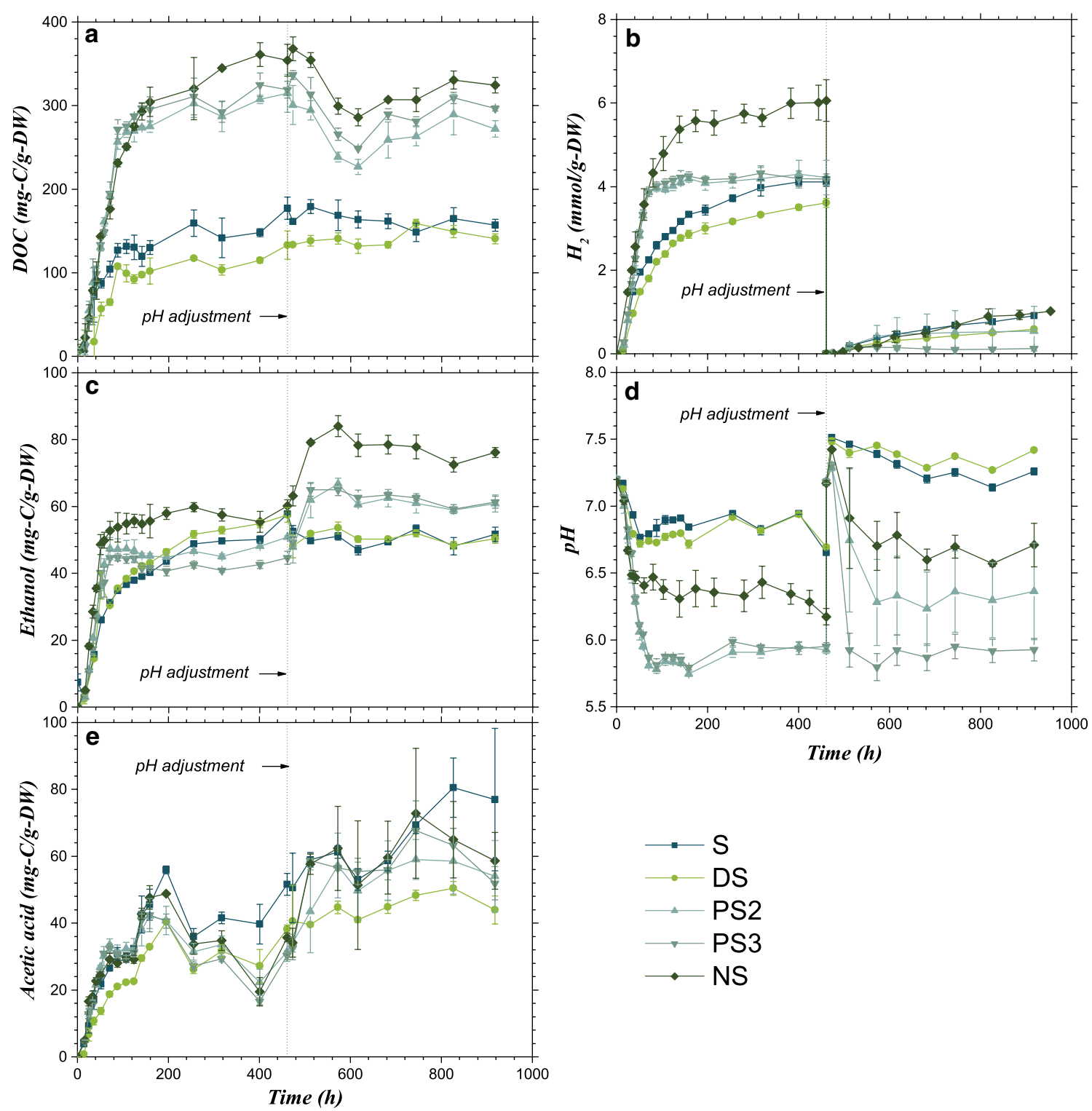

Fig. 1 Yields of metabolites from anaerobic fermentation of untreated and pretreated straw. a Dissolved organic carbon, b hydrogen, c ethanol, d $\mathrm{pH}$, and e acetate. Error bar represents the standard deviation from three independent incubation batches 
respectively. PAA pretreatment increased the ultimate yields of ethanol by 15.5 and $12.5 \%$ with treatment for 2 and $3 \mathrm{~h}$, but decreased the yields of $\mathrm{H}_{2}$ by 21.8 and $29.3 \%$ and decreased those of acetic acid by 26.6 and $15.9 \%$, respectively. Only the NS pretreatment increased the ultimate yields of $\mathrm{H}_{2}$ and ethanol by 16.3 and $45.5 \%$, respectively, and decreased that of acetic acid by $9.5 \%$. Overall, the carbon conversion yield of liquid metabolites (including ethanol and acetic acid) increased by $13.5 \%$ for NS and decreased by $21.9,9.0$, and $4.0 \%$ for DS, PS2, and PS3, respectively.

Nevertheless, the acidogenesis rates were accelerated during the first 60 days except for DS. The maximum generation rates, in the order of S, DS, PS2, PS3, and NS, were $0.041,0.029,0.057,0.058$, and $0.062 \mathrm{mmol} /$ (g-DW h) for $\mathrm{H}_{2}$ (Fig. 1b); 0.50, 0.70, 0.73, 0.80, and $0.97 \mathrm{mg}-\mathrm{C} /(\mathrm{g}-\mathrm{DW} \mathrm{h})$ for ethanol (Fig. 1c); and 0.47 , $0.30,0.54,0.55$, and $0.66 \mathrm{mg}-\mathrm{C} /(\mathrm{g}-\mathrm{DW} \mathrm{h})$ for acetic acid (Fig. 1e), respectively. As a result, the $\mathrm{pH}$ decreased sharply for PS2, PS3, and NS (Fig. 1d). However, NS pretreatment obviously enhanced the buffer capacity.

In order to understand the yields of metabolites and the shifts in the metabolic pathway produced by substrate pretreatment, the measurements discussed in the following sections focused on the characterization of the properties of substrates after different pretreatments.

\section{Biochemical compositions and specific surface areas of substrates}

Table 1 shows the biochemical compositions and specific surface areas of untreated and pretreated rice straw. As expected, dilute acid pretreatment removed almost all hemicellulose as well as some ash and lignin, as indicated by the increased ratio of cellulose to lignin (3.44 compared with 3.08 of S). PAA pretreatment removed almost all lignin and some hemicellulose, while increasing the pretreatment time from 2 to $3 \mathrm{~h}$ only removed further hemicellulose but not lignin. Alkali treatment after PAA treatment could further reduce the content of ash and hemicellulose.
The specific surface area determined by the Langmuir equation was about 1.5-1.6 times the value determined by the BET equation. Nevertheless, both methods show the same trend, namely that the specific surface area increased eightfold after dilute acid pretreatment, doubled after PAA pretreatment, and was reduced by $10 \%$ by NS pretreatment.

Specific surface area is usually regarded as being positively correlated with the accessibility to holocellulose [3]. Unfortunately, the present study demonstrated the reverse phenomenon, i.e., the substrate after NS pretreatment possessed less surface area but had the highest valorization efficiency. In comparison, although dilute acid pretreatment improved the surface area greatly, it did not enhance the subsequent fermentation. Although hemicellulose and lignin are the two components that are regarded as limiting the accessibility to cellulose [3], the reduction in the hemicellulose limitation after dilute acid treatment did not improve hydrolysis or acidogenesis, whereas the reduction in the lignin limitation after PAA treatment did improve hydrolysis. However, the enhancement of acidogenesis contributed more to cellulose modification in the NS treatment.

\section{Micro-morphological structure of straws before and after fermentation}

The interior and exterior surfaces of straws were observed by SEM before fermentation (Fig. 2). As noted, for PS3 and NS, the straw pieces were too thin to allow distinction between the interior and exterior surfaces. As expected, in the order of S, DS, PS2, PS3, and NS, the epidermis was increasingly exfoliated. In the case of the DS interior surface, vascular bundles were exposed to some extent but were still connected by cuticle and parenchyma, and covered with some lignin droplets. Amounts of vascular bundles were clearly observed for PS-treated straws, but longer treatment times led to increased roughness of the bundles. For NS, the fiber bundles with diameters of 3-5 $\mu \mathrm{m}$ were completely liberated, and some were fractured, and more cellulose fibers

Table 1 Biochemical components and specific surface area of rice straw

\begin{tabular}{|c|c|c|c|c|c|c|}
\hline Parameter & Unit & $\mathrm{S}$ & DS & PS2 & PS3 & NS \\
\hline \multicolumn{7}{|c|}{ Biochemical components } \\
\hline Hemicellulose & g/g-DW & $0.346 \pm 0.000$ & $0.022 \pm 0.000$ & $0.111 \pm 0.005$ & $0.071 \pm 0.001$ & $0.085 \pm 0.003$ \\
\hline Cellulose & g/g-DW & $0.406 \pm 0.002$ & $0.725 \pm 0.003$ & $0.659 \pm 0.005$ & $0.762 \pm 0.001$ & $0.811 \pm 0.003$ \\
\hline Lignin & g/g-DW & $0.132 \pm 0.005$ & $0.211 \pm 0.000$ & $0.031 \pm 0.001$ & $0.037 \pm 0.000$ & $0.029 \pm 0.003$ \\
\hline Ash & g/g-DW & $0.067 \pm 0.014$ & $0.036 \pm 0.002$ & $0.068 \pm 0.001$ & $0.076 \pm 0.000$ & $0.015 \pm 0.002$ \\
\hline \multicolumn{7}{|c|}{ Specific surface area } \\
\hline BET & $\mathrm{m}^{2} / \mathrm{g}-\mathrm{DW}$ & 0.887 & 8.021 & 1.899 & 1.911 & 0.793 \\
\hline Langmuir & $\mathrm{m}^{2} / \mathrm{g}-\mathrm{DW}$ & 1.409 & 11.995 & 2.844 & 2.875 & 1.224 \\
\hline
\end{tabular}



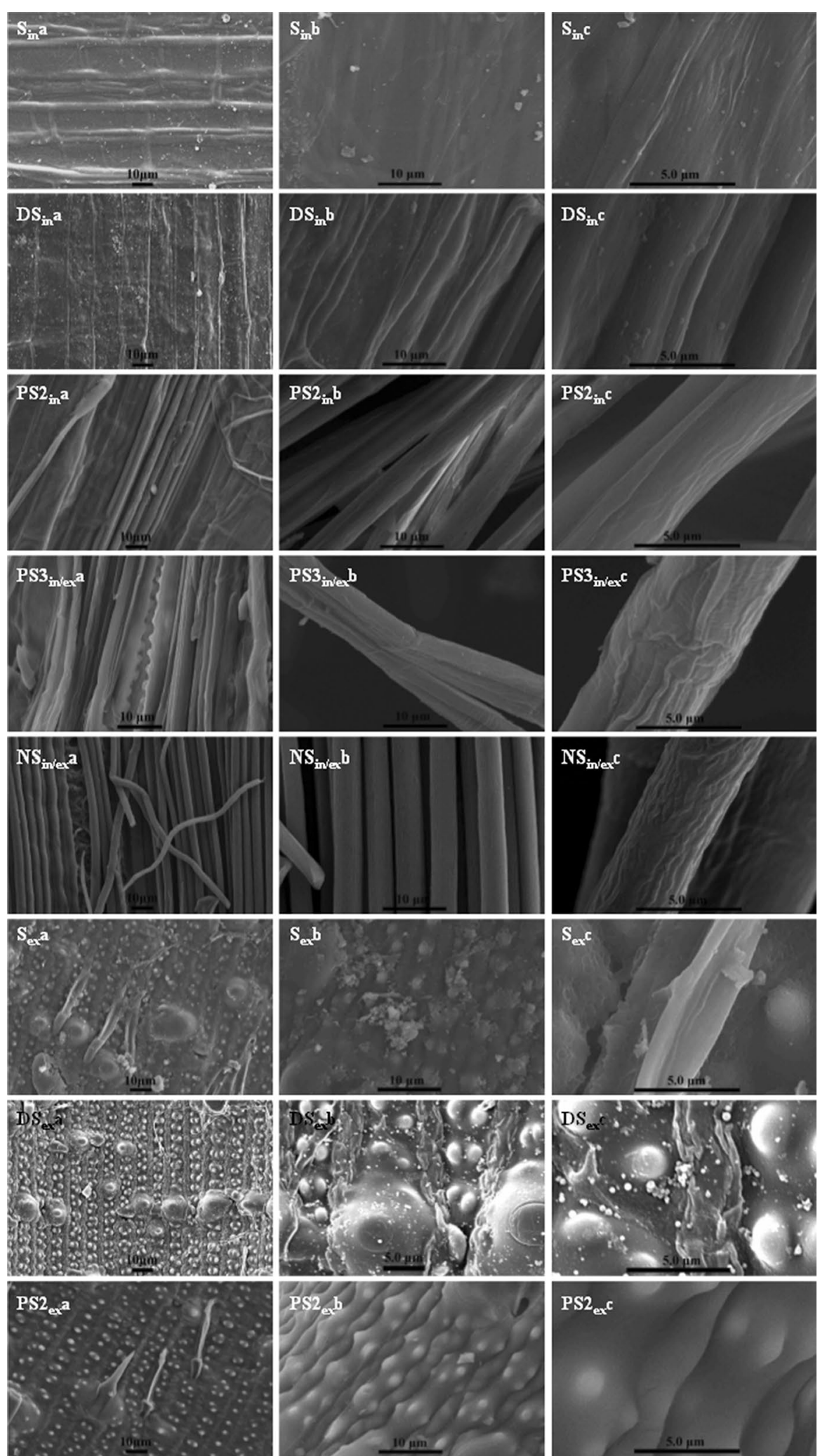

Fig. 2 SEM images of the interior and exterior surfaces of straw before fermentation. In interior; Ex exterior; In/Ex too thin to be distinguished from the interior or exterior surface 
with a diameter of $0.2-0.5 \mu \mathrm{m}$ appeared on the bundles, leading to increased roughness of the bundles. As to the exterior surface, DS pretreatment led to the exfoliation of the epidermis and then the appearance of nodules and a mastoid structure; furthermore, lignin droplets were regenerated during dilute acid pretreatment [28]. In contrast, the exterior surface of PS2 straw had more vascular bundles exposed, the nodules and mastoid structure were partially dissolved, and the lignin droplets were not observed.

Slices of straws were observed by TEM and AFM (Fig. 3). The cell wall of the untreated straw was composed of sheets of parenchyma cells and bundle sheath cells that have a compact structure. Dilute acid pretreatment resulted in the appearance of pores, looseness of the walls, and obvious shrinking of the secondary cell walls. PAA pretreatment resulted in the removal of substances in intercellular layers and lumens, and the fracture of bundle sheath shells. Further NS pretreatment resulted in the severe shrinking of bundle sheath cells and complete destruction of the original structure, i.e., the structural substances were repartitioned. Meanwhile, the roughness estimated from AFM images suggested that NS pretreatment led to the greatest roughness, i.e., the maximum, average, and root mean square values were $175,15.2$, and $18.6 \mathrm{~nm}$, while those of the PS2 sample were 93.9, 8.13, and $10.6 \mathrm{~nm}$, and those of the PS3 sample were 71.1, 5.95, and $7.56 \mathrm{~nm}$, respectively.

The corresponding SEM images of straw samples after fermentation are shown in Fig. 4. Bacterial degradation damaged the epidermis of $S$ straw, revealing abundant bundles and a porous structure. For DS, the bundles and pores were recovered or refilled by fragments. The bare bundles of PS2 straw were greatly destroyed and covered by $C$. thermocellum cells. In the case of PS3, the bundles were dispersed with the diameters being reduced to $0.5-1.5 \mu \mathrm{m}$. For the NS sample, no cellulose fibers could be observed in the residue, which was spongy and full of C. thermocellum cells. Although the exterior surfaces of the straw were highly recalcitrant to bacterial attack, they showed similar exposure of bundles and some fracturing of nodules and mastoid structure after fermentation. Therefore, $C$. thermocellum utilized the straw in a processive way from outside gradually to inside.

\section{Functional groups on the lignocellulosic surface}

The carbon in cellulose is bound to $\mathrm{O}$ by $\mathrm{C}-\mathrm{O}$ or $\mathrm{C}=\mathrm{O}$ bonds, while $\mathrm{C}-\mathrm{C}$ bonds mainly appear in hemicellulose, lignin, and other contaminants. Therefore, the relative proportion of $\mathrm{C}-\mathrm{C}$ bonds in lignocellulose can represent the level of cellulose contamination by lignin or hemicellulose $[29,30]$. The C1s zone of the XPS spectrum in the range of 282-291 eV binding energy displayed four peaks corresponding to the bonds of $\mathrm{C}-(\mathrm{C}, \mathrm{H})(284.8 \pm 0.1 \mathrm{eV})$, $\mathrm{C}-\mathrm{O}(286.3 \mathrm{eV}), \mathrm{C}=\mathrm{O}(\mathrm{O}-\mathrm{C}-\mathrm{O})(288.2 \pm 0.2 \mathrm{eV})$, and $\mathrm{COOH}(289.0 \mathrm{eV})$ (Fig. 5). To avoid peak overlap and to identify the individual contributions of each bond, the peaks were fitted using XPS PEAK 4.1 software. The results of spectrum fitting are shown in Table 2. There are minor differences in the values for exterior surfaces among S, DS, and PS2. In contrast, the distribution of bonds across the interior surfaces was greatly altered by pretreatments. Compared to $\mathrm{S}$, the proportion of $\mathrm{C}-$ $(\mathrm{C}, \mathrm{H})$ bonds was reduced by $41.3,46.8,57.6$, and $47.0 \%$, respectively, in DS, PS2, PS3, and NS. C-O bond proportions were increased by $120-175 \%$ and those of $\mathrm{C}=\mathrm{O}(\mathrm{O}-$ $\mathrm{C}-\mathrm{O})$ bonds were increased by $145-183 \%$. Although the proportion of $\mathrm{COOH}$ bonds was reduced by $7-55 \%$, their original proportion in $\mathrm{S}$ was low at $4.09 \%$. Therefore, all four pretreatments effectively removed the constraints of hemicellulose or lignin on cellulose accessibility. Compared with PAA alone, the subsequent alkali pretreatment had a negligible effect on hemicellulose and lignin.

Higher values of the atomic ratio of $\mathrm{O} / \mathrm{C}$ or the ratio of $\mathrm{C}-\mathrm{O}$ bonds to $[\mathrm{C}=\mathrm{O}(\mathrm{O}-\mathrm{C}-\mathrm{O})+\mathrm{COOH}]$ bonds can indicate higher contents of cellulose. The values of both indicators were slightly reduced for the exterior surfaces and significantly increased for the interior surfaces by pretreatments. Noticeably, the values for NS were lower than those for PS2 and PS3, although the biochemical components suggested higher cellulose content (Table 1). This implies that the increased cellulose content could mainly be attributed to decreased ash.

\section{Modification of cellulose biomolecules by pretreatments} Figure 6 shows the CP/MAS ${ }^{13} \mathrm{C}$ NMR spectra of straw fibers. The positions of carbon atoms in a glucose unit of cellulose are marked as C1-C6 (Fig. 6). The chemical shifts, $\delta$, may be assigned as follows: $\mathrm{C} 1(98-109 \mathrm{ppm})$, C4 (80-91 ppm), C2/C3/C5 (68-80 ppm), and C6 (58$68 \mathrm{ppm})$. For C6, $\delta$ in the $64.5-66.0 \mathrm{ppm}$ region originates from type I cellulose. For $\mathrm{C} 1, \delta$ in the $106-107 \mathrm{ppm}$ region originates from type II cellulose. To avoid peak overlaps and to identify the characteristic peaks, spectrum fitting was applied using the software MestReC-V 4.9.9.9 for the spectral regions of $\mathrm{C} 1$ and C6. The fitting results are listed in Table 3. Since $\delta$ in the $80-86 \mathrm{ppm}$ region originates from amorphous cellulose and $\delta$ in the $86-91 \mathrm{ppm}$ region originates from crystalline cellulose, the crystallinity index $\mathrm{CrI}$ is defined as the ratio of the peak area in the $86-91 \mathrm{ppm}$ region to that in the $80-91 \mathrm{ppm}$ region. The CrI values are also listed in Table 3.

The most significant changes appeared for NS pretreatment, where the proportion of type I cellulose decreased from $28.1 \%$ in $\mathrm{S}$ to $7.91 \%$ in NS, while the undetected 

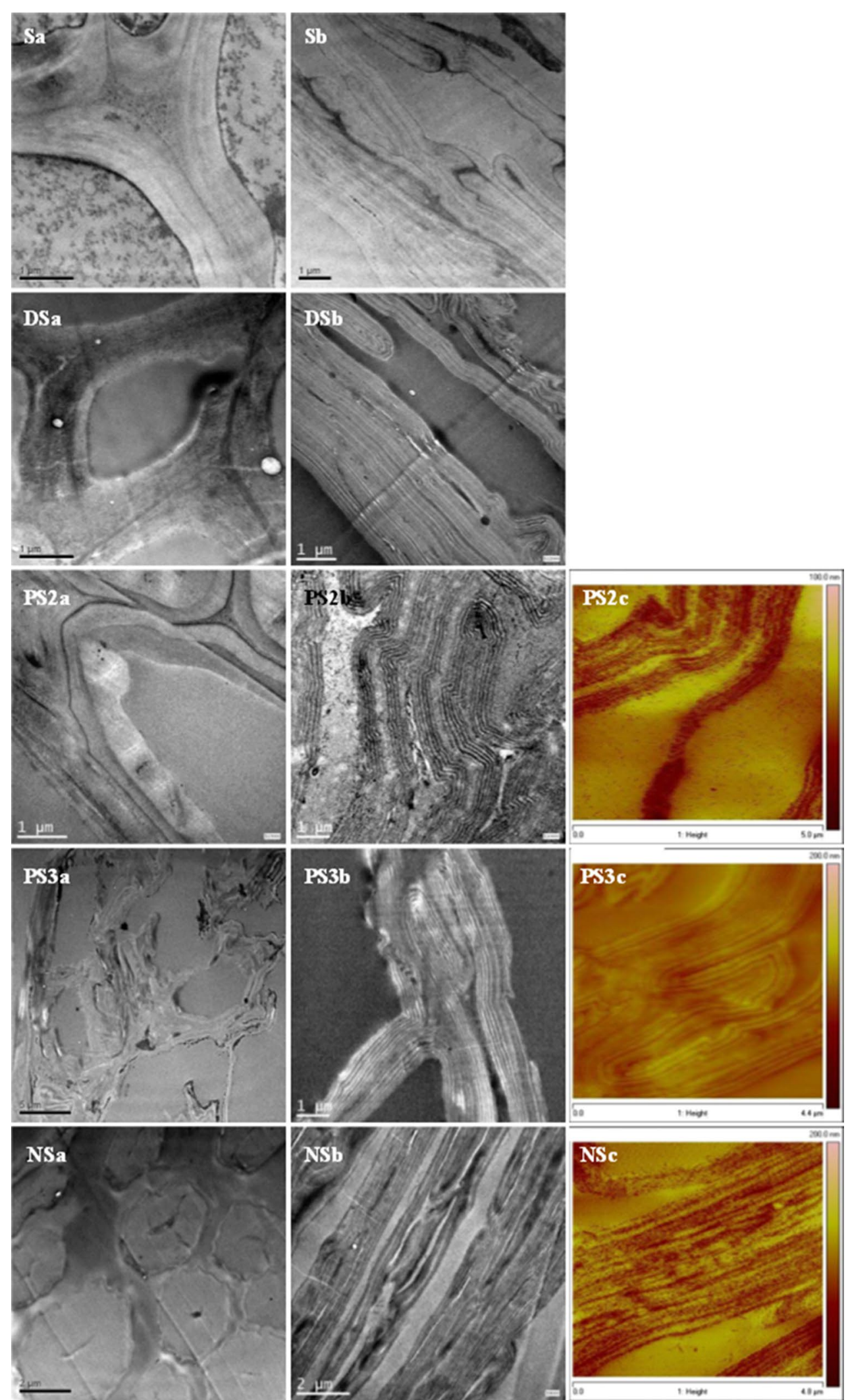

Fig. 3 TEM and AFM images of straw before fermentation. PS2C, PS3C, NSC: AFM images 

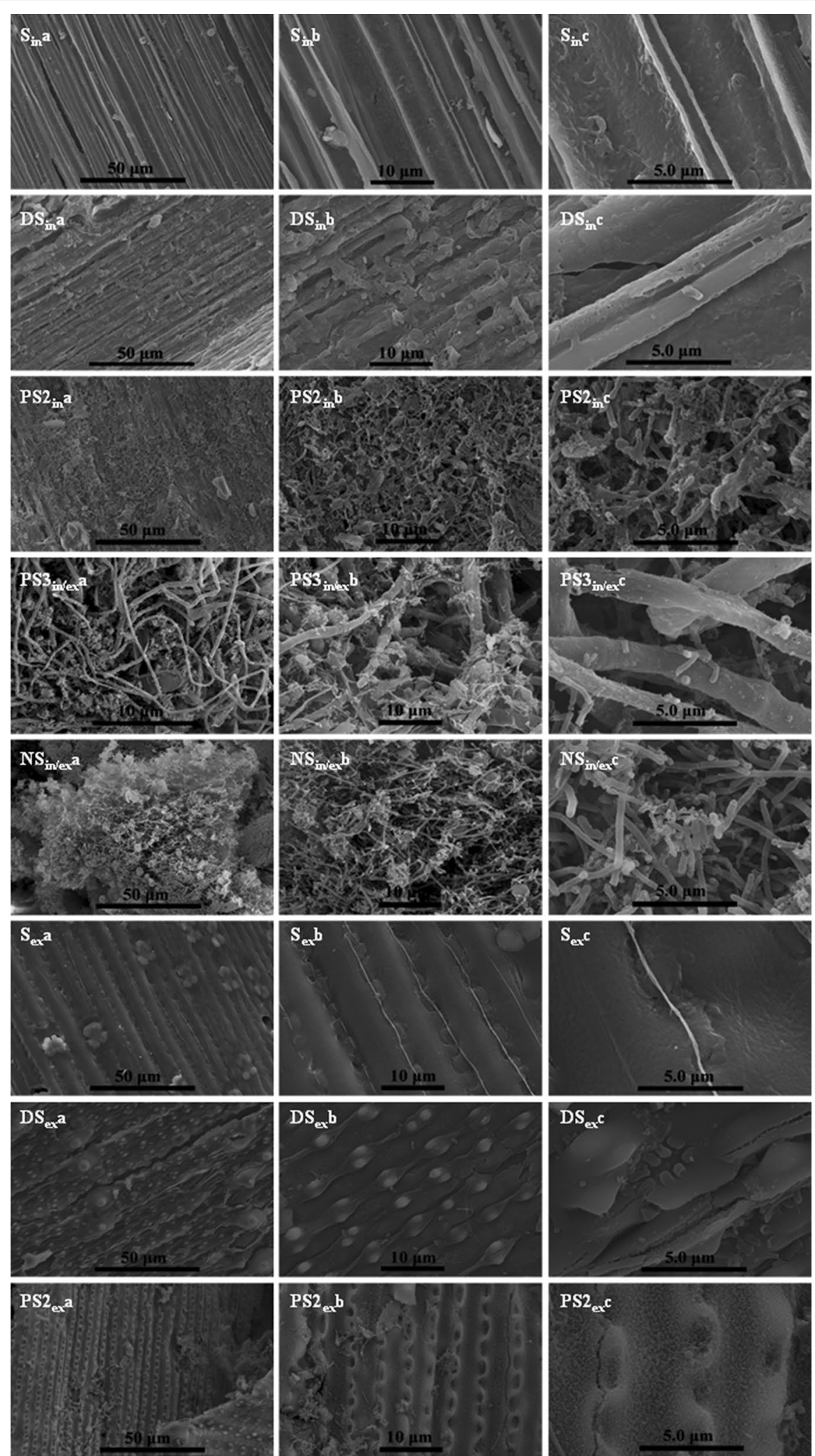

Fig. 4 SEM images of the interior and exterior surfaces of straw after fermentation. In interior; Ex exterior; In/Ex too thin to be distinguished from the interior or exterior surface 


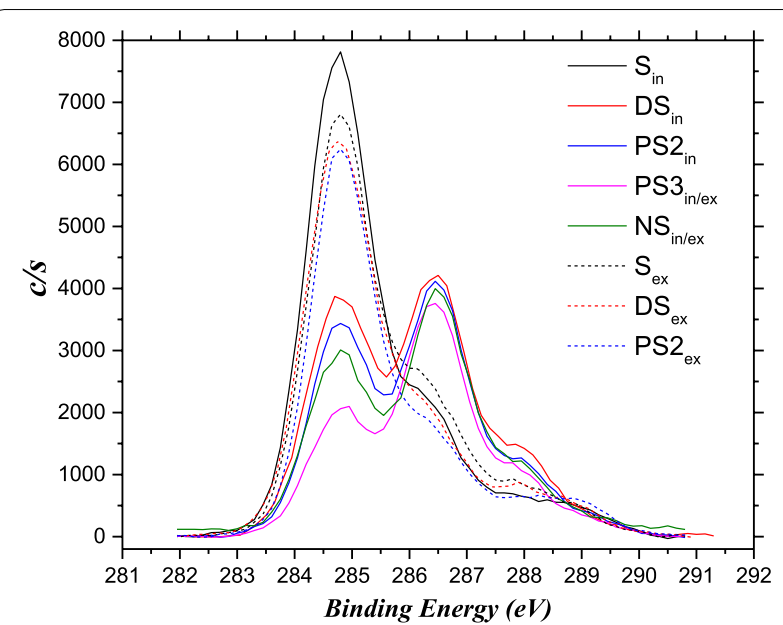

Fig. 5 XPS C1s spectrum of straws. In interior; Ex exterior; In/Ex too thin to be distinguished from the interior or exterior surface

type II cellulose in S increased to $11.8 \%$ in NS. Furthermore, the ratio of $I_{\beta}-I_{\alpha}$ increased upon pretreatment, i.e., to $0.25,0.45,0.74,1.48$, and 5.56 , respectively, for S, DS, PS2, PS3, and NS. Thus, NS pretreatment modified type I cellulose to type II [16] and other crystalline or amorphous celluloses. As cellulose II has more amorphous regions than cellulose I [31], it is understandable that $\mathrm{CrI}$ of NS was reduced by $53 \%$. Comparatively, DS increased the proportion of type I cellulose by $31 \%$ and CrI by $29 \%$. PAA pretreatment increased CrI by only $7-16 \%$.

The degree of polymerization of the cellulose was assessed by the indicators of weight-average $\mathrm{DP}_{\mathrm{w}}$ and weight-average $\mathrm{DP}_{\mathrm{n}}$. As listed in Table 4, DS decreased $\mathrm{DP}_{\mathrm{w}}, \mathrm{DP}_{\mathrm{n}}$, and polydispersity the most. PAA pretreatment for $2 \mathrm{~h}$ decreased the values of the above three parameters, while longer operation resulted in a gradual increase in the values. NS conversely increased $\mathrm{DP}_{\mathrm{n}}$ and the polydispersity, implying that NS depolymerized cellulose and then polymerized it again.

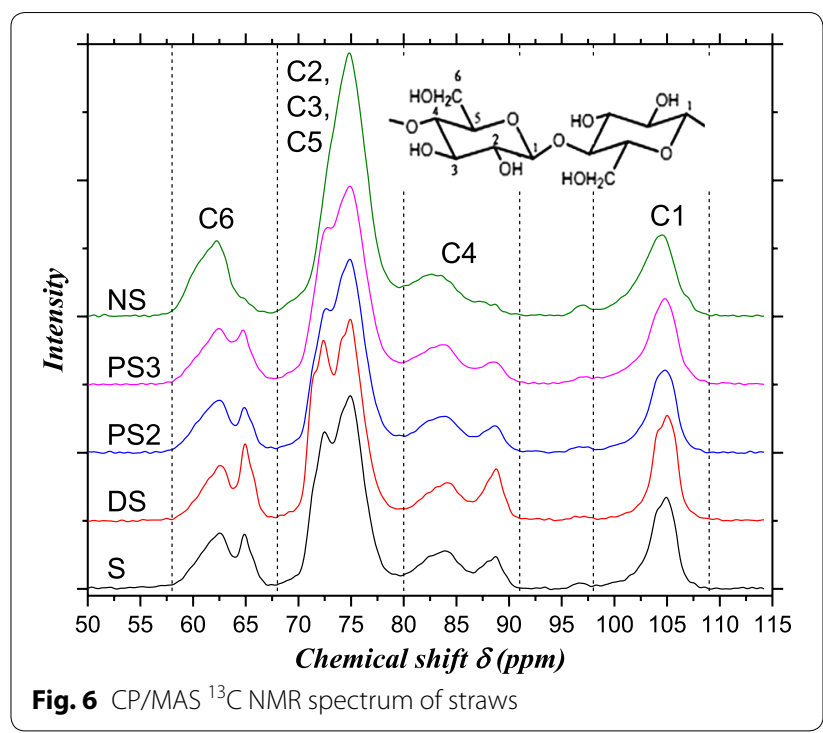

\section{Biodegradability of substrates and residues}

Since TGC labeling utilizes the binding of fluorescent cellulose-binding module 3 (CBM3) protein to lignocellulosic material, the green fluorescence intensity implies the proportion of the surface accessible to CBM3. The increased fluorescence intensities of the pretreated substrates in Fig. $7 \mathrm{~b}$ indicate that more accessible surfaces were exposed by the pretreatments, and especially by PS3 and NS. The difference between Fig. 7a without BSA blocking and Fig. 7b with BSA blocking indicates the contribution from non-productive binding to lignin. Therefore, if estimated according to the mean fluorescence intensity, $38 \%$ of the CBM3-accessible surface was non-productive owing to the sediment of lignin droplets. Comparatively, the fluorescence differences between Fig. 7a and Fig. 7b for PS2, PS3, and NS were not evident, suggesting that the contribution of lignin could

Table 2 Functional groups of the lignocellulosic surface

\begin{tabular}{|c|c|c|c|c|c|c|}
\hline \multirow[t]{2}{*}{ Samples } & \multicolumn{4}{|c|}{ Proportion of bonds (\%) } & \multirow[t]{2}{*}{$\mathrm{O} / \mathrm{C}$ atomic ratios } & \multirow{2}{*}{$\begin{array}{l}\text { Ratio of } \mathrm{C}-\mathrm{O} \text { to }[\mathrm{C}=\mathrm{O}(\mathrm{O}-\mathrm{C}- \\
\mathrm{O})+\mathrm{COOH}]\end{array}$} \\
\hline & $\mathrm{C}-(\mathrm{C}, \mathrm{H})$ & $\mathrm{C}-\mathrm{O}$ & $\mathrm{C}=\mathrm{O}(\mathrm{O}-\mathrm{C}-\mathrm{O})$ & $\mathrm{COOH}$ & & \\
\hline \multicolumn{7}{|l|}{ Interior } \\
\hline$S_{\text {in }}$ & 71.42 & 19.05 & 5.43 & 4.09 & 0.63 & 2.00 \\
\hline $\mathrm{DS}_{\text {in }}$ & 41.93 & 41.83 & 14.00 & 2.24 & 1.25 & 2.58 \\
\hline$P S 2_{\text {in }}$ & 37.99 & 44.92 & 13.30 & 3.79 & 1.34 & 2.63 \\
\hline$P S 3_{\text {in }}$ & 30.25 & 52.39 & 13.70 & 3.67 & 1.49 & 3.02 \\
\hline$N S_{\text {in }}$ & 37.84 & 44.95 & 15.38 & 1.83 & 1.27 & 2.61 \\
\hline \multicolumn{7}{|l|}{ Exterior } \\
\hline $\mathrm{S}_{\mathrm{ex}}$ & 67.04 & 21.98 & 8.03 & 2.95 & 0.86 & 2.00 \\
\hline $\mathrm{DS}_{\mathrm{ex}}$ & 69.32 & 19.31 & 7.10 & 4.28 & 0.82 & 1.70 \\
\hline$P S 2_{\text {ex }}$ & 67.40 & 21.64 & 5.67 & 5.29 & 0.67 & 1.97 \\
\hline
\end{tabular}


Table 3 Proportion of different crystalline cellulose and the Crl of cellulose

\begin{tabular}{|c|c|c|c|c|c|c|}
\hline \multirow[t]{2}{*}{ Crystalline types } & \multirow[t]{2}{*}{ Chemical shift (ppm) } & \multicolumn{5}{|c|}{ Proportion (\%) } \\
\hline & & $S$ & DS & PS2 & PS3 & NS \\
\hline Cellulose I (C6) & $64.5-66.0$ & 28.1 & 36.9 & 27.4 & 32.0 & 7.91 \\
\hline Cellulose II (C1) & $106.0-107.0$ & $N D^{a}$ & $N D^{a}$ & $N D^{a}$ & $N D^{a}$ & 11.8 \\
\hline Cellulose $I_{a}(\mathrm{C} 1)$ & $104.9(0.1)$ & 62.5 & 59.6 & 43.7 & 35.1 & 8.90 \\
\hline Cellulose $I_{\beta}(\mathrm{C} 1)$ & $105.9,103.8$ & 15.8 & 26.8 & 32.2 & 51.9 & 49.5 \\
\hline Less-ordered (C1) & $103.2,102.6(0.2) 21.7$ & 21.7 & 13.6 & 24.1 & 13.0 & 27.8 \\
\hline Crystallinity index $\mathrm{Crl}$ & & 35.4 & 45.8 & 32.8 & 29.6 & 16.8 \\
\hline
\end{tabular}

${ }^{a}$ ND Not detected

Table 4 Polymerization degree of cellulose

\begin{tabular}{llllll}
\hline Polymerization degree & S & DS & PS2 & PS3 & NS \\
\hline $\mathrm{DP}_{\mathrm{w}}$ & 190 & 58 & 152 & 153 & 168 \\
$\mathrm{DP}_{\mathrm{n}}$ & 553 & 115 & 375 & 440 & 776 \\
Polydispersity & 2.91 & 1.99 & 2.47 & 2.87 & 4.61 \\
\hline
\end{tabular}

be ignored in these pretreated substrates. Meanwhile, the adhesive mass among vascular bundles in DS disappeared after PAA pretreatment. As a result, the images revealed that the closely packed vascular bundles of PS3and NS-pretreated substrates were all covered by green proteins, and fractures in the bundles were obvious for NS.

The remaining residues after straw fermentation were still fluorescent to different extents (Fig. 7c with BSA blocking). S and DS residues displayed lower fluorescent intensities than the substrates but still retained a similar morphology. PS residues showed green fractured bundles that should theoretically be accessible to cellulase. As for NS, only some debris remained.

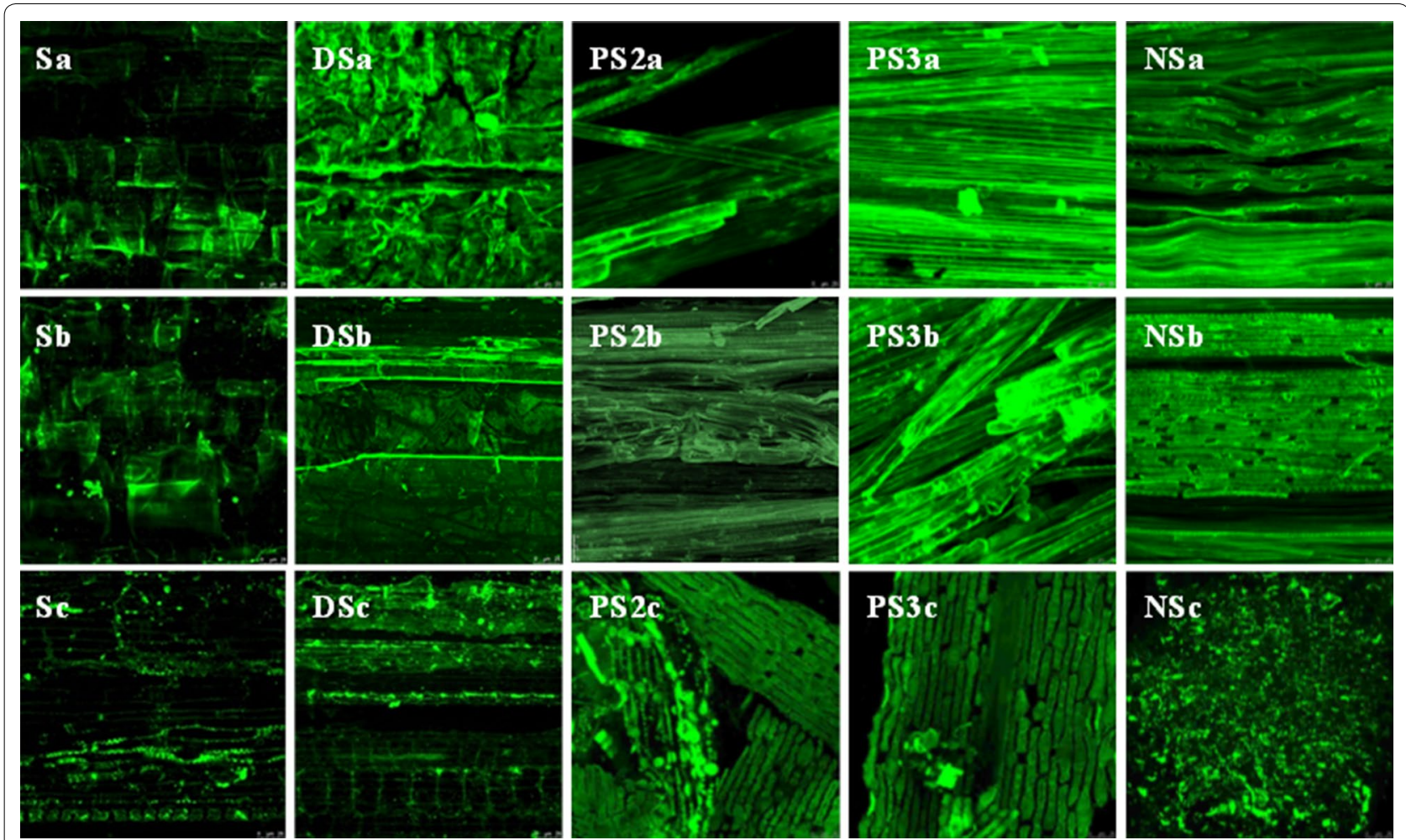

Fig. 7 TGC labeling on lignocellulosic surfaces: a straw before fermentation, without BSA blocking; b straw before fermentation, with BSA blocking; and $\mathbf{c}$ straw after fermentation, with BSA blocking 


\section{Discussion}

\section{Influence of pretreatment on hydrolysis}

The average carbon contents of cellulose and rice straw are about $41.8 \%$ DW [32] and 48.7\% DW [33], while the maximal DOC yields reached $368 \pm 14 \mathrm{~g}-\mathrm{C} / \mathrm{g}-\mathrm{DW}$ for NS (Fig. 1). Considering that $21-27 \%$ of the cellobiose will be used for biosynthesis to give biomass and extracellular enzymes [34], the hydrolysis efficiency of NSpretreated straw was thus close to $100 \%$. Compared with PS3-pretreated straw, whose lignin and hemicellulose contents (Table 1) and accessibility (Fig. 7) were roughly equivalent to those of NS, a $10 \%$ increment in DOC indicated that the hydrolysis efficiency for NS could be attributed to the modification of cellulose from type I to type II and from $I_{\alpha}$ to $I_{\beta}$ (Table 3 ), its lower CrI (Table 3) and smaller diameter and fracture of its vascular bundles (Figs. 2, 3), and the reduction in the amount of ash (Table 1). Since cellulose II has more accessible crystal surfaces [31] and amorphous regions [31], lower CrI [18] and smaller nanowhiskers [35] than cellulose I, the digestibility evaluated by cellulase $[11,16-18]$ is higher for type II than type I cellulose. Meanwhile, the reduction in silica components (as suggested by the reduced ash content for NS) can improve enzymatic hydrolysis [36]. Furthermore, alkaline pretreatment can modify lignin by cleaving $\beta-O-4$ linkages, resulting in the formation of new phenolic hydroxyl groups, which leads to a substantial decrease in the molecular mass of the residual lignin and a more hydrophilic character [37]. Alkaline pretreatment can also remove the acetyl groups of hemicellulose [38]. As noted, the hydrolysis benefit from the additional alkaline treatment was not significant at the beginning because the DOC generation rates were nearly equal for PS2, PS3, and NS.

Delignification by PAA seemed to be the most effective means of enhancing the hydrolysis efficiency (Fig. 1; Table 1), where the maximal DOC yields of PS2 and PS3 were 76 and $88 \%$, respectively, higher than that of $\mathrm{S}$. In comparison, although dilute sulfuric acid removed almost all of the hemicellulose (Table 1), expanded the specific surface area eightfold (Table 1), and depolymerized the cellulose to a quarter degree (Table 4), DS pretreatment led to the formation of sediments of lignin droplets (Figs. 2, 3), increased the proportion of type I cellulose, and increased the cellulose CrI (Table 3). As a result, the productive CBM3 accessibility (Fig. 3) and bacterial hydrolysis efficiency (Fig. 1) were not improved by DS pretreatment.

\section{Properties of cellulose affect the metabolic pathway and efficiency}

With regard to lignocellulosic feedstock, their theoretical ethanol yields are usually calculated from the hemicellulose and cellulose contents [39]. It is understandable that the fermentation efficiency of a 5-carbon hemicellulose is different from that of a 6-carbon cellulose $[40,41]$. C. thermocellum expressed different cellulosomal patterns [42] and global gene patterns [43, 44 ] when grown on either cellulose or cellobiose, corresponding to the slightly varied ratios of ethanol to acetate products when grown on cellulose, cellobiose, or cellodextrin with different degrees of polymerization [45]. The ethanol potential of lignocellulosic biomass after pretreatment varies and is difficult to predict owing to interactions between several factors [3]. However, to the best of our knowledge, no previous report has definitively pointed out that the crystalline form of cellulose can alter the fermentation pathway. Again, taking NS- and PS3pretreated straws for comparison, the ultimate ethanol, $\mathrm{H}_{2}$, and acetate yields of NS were, respectively, 29, 65, and $8 \%$ higher than that of PS3 (Fig. 1), which could not be attributed to the $10 \%$ increment in hydrolysis efficiency. Obviously, NS dominated by cellulose II and $I_{\beta}$ was more favorable for $\mathrm{H}_{2}$ and ethanol production than PS3 dominated by cellulose $I$ and $I_{\alpha}$. Therefore, the crystalline form altered the susceptibility of cellulose to bio-oxidation. In contrast, Carlsson et al. [46] observed that $I_{\alpha}$ - and $I_{\beta^{-}}$ dominated cellulose did not differ in susceptibility to oxidation by 2,2,6,6-tetramethylpiperidine-1-oxyl. Hence, cellulose transformation should be another important driving force for enhancing the production rates and yields of $\mathrm{H}_{2}$ and methanol.

\section{Pretreatment led to an increase in low-value by-products or pollutants}

Notably, at the end of $900 \mathrm{~h}$ of fermentation, a portion of the hydrolysates remained unused by $C$. thermocellum, indicated by the fact that the carbon contents of ethanol and acetic acid could only cover $82 \%$ of DOC for S, $68 \%$ for DS, and 43-45\% for PS2, PS3, and NS. (Note: other acids were detected in small amounts; data not shown). Lynd et al. [47] noticed that for many studies the carbon balance was not close and indeed was $<70 \%$ when accounting for commonly measured fermentation products of $C$. thermocellum incubation. The authors further determined that $11.1 \%$ of the unbalanced carbon in the liquids originated from malate, pyruvate, uracil, soluble glucans, and extracellular free amino acids for a 60-h $C$. thermocellum incubation [47]. Carbon flux distribution for cellulose fermentation by $C$. cellulolyticum $[48,49]$ and the metabolome of $C$. thermocellum [50] supported the generation of extracellular proteins/polysaccharides/ pyruvate and free amino acids in large quantities.

Substrate availability could affect the gene expression of $C$. thermocellum and might therefore regulate the metabolism, because the composition of cellulosome and 
other hydrolytic enzymes in C. thermocellum has been found to be dependent on carbon sources (dilute acidpretreated switchgrass, cellobiose, amorphous cellulose, crystalline cellulose, and combinations of crystalline cellulose with pectin and/or xylan [51]; crystalline cellulose and non-cellulosic substrates, low substrate availability [52]). It has been reported that the cellulosomal genes are regulated by the presence of extracellular polysaccharides via an external carbohydrate-sensing mechanism [53]. As a result, a series of metabolic by-products, which are not usually associated with $C$. thermocellum fermentation, including malate, pyruvate, uracil, soluble glucans, and extracellular free amino acids [47], could be detected at different extents. Furthermore, exposure to ethanol could further change the transcriptomics, proteomics, and metabolomic profiles of $C$. thermocellum [54].

That is to say, although pretreatment may improve the hydrolysis efficiency to different extents, the hydrolysates produced in increased amounts are not converted to the targeted ethanol or acetate, but to unfavorable substrates for the selected consortium or to low-value by-products, which are difficult resources to value, and finally have to be regarded as wastewater. As a result, the benefits afforded by the improved digestibility following pretreatment are severely reduced by the added requirement for wastewater treatment. Even acetate is difficult to separate and use, owing to its high hydrophilicity, which leads to its limited applications as feedstock for methanization, as a carbon source for biological nutrient removal from wastewater [55], or as a participant in chain elongation to medium-chain carbon products [56].

Compared with $\mathrm{S}$, ethanol production was increased by $15.5,12.5$, and $45.5 \%$, respectively, through PS2, PS3, and NS pretreatment. However, the aqueous non-ethanol DOC production was increased by 104,122 , and $136 \%$, resulting in a huge burden for wastewater treatment.

Additional file 1 shows a sketch diagram of the effect of precise pretreatment on substrate characteristics, hydrolysis, fermentation, and trade-off between energy benefits and pollution.

\section{Conclusion}

The transformation of cellulose crystalline forms from I to II and from $I_{\alpha}$ to $I_{\beta}$ is essential to improving the production of $\mathrm{H}_{2}$ and ethanol. Meanwhile, pretreatment not only increased the yield of the targeted products, but also expanded the yield of unwanted by-products to a greater extent. Therefore, the effectiveness of pretreatment should not only be determined according to energy auditing and effects of the accompanying inhibitors, but should also be assessed in terms of the environmental benefits of the whole integrated system.

\section{Additional file}

Additional file 1. Graphic Abstract. It contains a sketch diagram about the effect of pretreatment on hydrolysis, fermentation and potential pollution.

\section{Abbreviations \\ BSA: bovine serum albumin; CBM3: cellulose-binding module 3; DOC: dis- solved organic carbon; DS: dewaxed rice straw pretreated with dilute sulfuric acid; DW: dry weight; NS: dewaxed rice straw pretreated with peracetic acid and then $\mathrm{NaOH}$; PAA: peracetic acid; PS: dewaxed rice straw pretreated with peracetic acid, PS2 for 2 h, and PS3 for 3 h; S: dewaxed rice straw; TGC: Trx- green fluorescent protein-CtCBM3; VS: volatile solid; wt: weight.}

\section{Authors' contributions}

FL and PH designed the experiments and wrote the manuscript. LC performed the experiments. LS participated in the data analysis. All authors read and approved the final manuscript.

\section{Author details}

1 State Key Laboratory of Pollution Control and Resource Reuse, Tongji University, Shanghai 200092, China. ${ }^{2}$ Institute of Waste Treatment and Reclamation, Tongji University, Shanghai 200092, China. ${ }^{3}$ Centre for the Technology Research and Training on Household Waste in Small Towns \& Rural Area, Ministry of Housing and Urban-Rural Development (MOHURD) of China, Shanghai 200092, China.

\section{Acknowledgements}

The authors would like to thank Ms. Yujing Wang for her help in sample preparation.

\section{Competing interests}

The authors declare that they have no competing interests.

\section{Availability of supporting data}

All data generated or analyzed during this study are included in this published article, and a supporting material "Additional file 1."

Consent for publication

All the authors consented on the publication of this work.

\section{Funding}

The authors would like to acknowledge the support from NSFC (51622809, 51378375, 21177096), Fundamental Research Funds for Central Universities (0400219341), and the Collaborative Innovation Center for Regional Environmental Quality.

\section{Publisher's Note}

Springer Nature remains neutral with regard to jurisdictional claims in published maps and institutional affiliations.

Received: 7 October 2016 Accepted: 5 April 2017

Published online: 11 April 2017

\section{References}

1. Carver SM, Nelson MC, Lepistö R, Yu Z, Tuovinen OH. Hydrogen and volatile fatty acid production during fermentation of cellulosic substrates by a thermophilic consortium at 50 and $60{ }^{\circ} \mathrm{C}$. Bioresour Technol. 2012;104:424-31.

2. Brethauer $\mathrm{S}$, Studer MH. Consolidated bioprocessing of lignocellulose by a microbial consortium. Energy Environ Sci. 2014;7(4):1446-53.

3. Singh R, Shukla A, Tiwari S, Srivastava M. A review on delignification of lignocellulosic biomass for enhancement of ethanol production potential. Renew Sustain Energy Rev. 2014;32:713-28. 
4. Pingali SV, Urban VS, Heller WT, McGaughey J, O'Neill H, Foston M, Myles DA, Ragauskas A, Evans BR. Breakdown of cell wall nanostructure in dilute acid pretreated biomass. Biomacromolecules. 2010;11(9):2329-35.

5. Baeyens J, Kang Q, Appels L, Dewil R, Lv Y, Tan T. Challenges and opportunities in improving the production of bio-ethanol. Prog Energy Combust Sci. 2015;47:60-88.

6. Jönsson LJ, Martín C. Pretreatment of lignocellulose: formation of inhibitory by-products and strategies for minimizing their effects. Bioresour Technol. 2016;199:103-12.

7. Alvira P,Tomás-Pejó E, Ballesteros M, Negro MJ. Pretreatment technologies for an efficient bioethanol production process based on enzymatic hydrolysis: a review. Bioresour Technol. 2010;101 (13):4851-61.

8. Chen X, Kuhn E, Jennings EW, Nelson R, Tao L, Zhang M, Tucker MP. DMR (deacetylation and mechanical refining) processing of corn stover achieves high monomeric sugar concentrations $\left(230 \mathrm{~g} \mathrm{~L}^{-1}\right)$ during enzymatic hydrolysis and high ethanol concentrations $(>10 \% \mathrm{v} / \mathrm{v})$ during fermentation without hydrolysate purification or concentration. Energy Environ Sci. 2016;9(4):1237-45.

9. Xu F, Sun J, Konda NVSNM, Shi J, Dutta T, Scown CD, Simmons BA, Singh S. Transforming biomass conversion with ionic liquids: process intensification and the development of a high-gravity, one-pot process for the production of cellulosic ethanol. Energy Environ Sci. 2016;9(3):1042-9.

10. Rollin JA, Zhu Z, Sathitsuksanoh N, Zhang YHP. Increasing cellulose accessibility is more important than removing lignin: a comparison of cellulose solvent-based lignocellulose fractionation and soaking in aqueous ammonia. Biotechnol Bioeng. 2011;108(1):22-30.

11. Cui T, Li J, Yan Z, Yu M, Li S. The correlation between the enzymatic saccharification and the multidimensional structure of cellulose changed by different pretreatments. Biotechnol Biofuels. 2014;7(1):1-10.

12. Xu N, Zhang W, Ren S, Liu F, Zhao C, Liao H, Xu Z, Huang J, Li Q, Tu Y, et al. Hemicelluloses negatively affect lignocellulose crystallinity for high biomass digestibility under $\mathrm{NaOH}$ and $\mathrm{H}_{2} \mathrm{SO}_{4}$ pretreatments in Miscanthus. Biotechnol Biofuels. 2012;5:58

13. Kim SB, Lee SJ, Lee JH, Jung YR, Thapa LP, Kim JS, Um Y, Park C, Kim SW. Pretreatment of rice straw with combined process using dilute sulfuric acid and aqueous ammonia. Biotechnol Biofuels. 2013;6:109.

14. Hall M, Bansal P, Lee JH, Realff MJ, Bommarius AS. Cellulose crystallinity - a key predictor of the enzymatic hydrolysis rate. FEBS J. 2010;277(6):1571-82.

15. Gao D, Chundawat SPS, Sethi A, Balan V, Gnanakaran S, Dale BE. Increased enzyme binding to substrate is not necessary for more efficient cellulose hydrolysis. Proc Natl Acad Sci. 2013;110(27):10922-7.

16. Mittal A, Katahira R, Himmel ME, Johnson DK. Effects of alkaline or liquidammonia treatment on crystalline cellulose: changes in crystalline structure and effects on enzymatic digestibility. Biotechnol Biofuels. 2011;4(1):1-16.

17. Samayam IP, Hanson BL, Langan P, Schall CA. Ionic-liquid induced changes in cellulose structure associated with enhanced biomass hydrolysis. Biomacromolecules. 2011;12(8):3091-8.

18. Cheng G, Varanasi P, Li C, Liu H, Melnichenko YB, Simmons BA, Kent MS, Singh S. Transition of cellulose crystalline structure and surface morphology of biomass as a function of ionic liquid pretreatment and its relation to enzymatic hydrolysis. Biomacromolecules. 2011;12(4):933-41.

19. Wang JP, Quirk A, Lipkowski J, Dutcher JR, Hill C, Mark A, Clarke AJ. RealTime observation of the swelling and hydrolysis of a single crystalline cellulose fiber catalyzed by cellulase 7B from Trichoderma reesei. Langmuir. 2012;28(25):9664-72.

20. Cheng G, Zhang X, Simmons B, Singh S. Theory, practice and prospects of $X$-ray and neutron scattering for lignocellulosic biomass characterization: towards understanding biomass pretreatment. Energy Environ Sci. 2015;8(2):436-55.

21. Chundawat SPS, Donohoe BS, da Costa Sousa L, Elder T, Agarwal UP, Lu F, Ralph J, Himmel ME, Balan V, Dale BE. Multi-scale visualization and characterization of lignocellulosic plant cell wall deconstruction during thermochemical pretreatment. Energy Environ Sci. 2011;4(3):973-84.

22. Chen W-H, Pen B-L, Yu C-T, Hwang W-S. Pretreatment efficiency and structural characterization of rice straw by an integrated process of dilute-acid and steam explosion for bioethanol production. Bioresour Technol. 2011;102(3):2916-24.

23. He P, Chai L, Li L, Hao L, Shao L, Lu F. In situ visualization of the change in lignocellulose biodegradability during extended anaerobic bacterial degradation. RSC Adv. 2013;3(29):11759-73.
24. Lu F, Ji J, Shao L, He P. Bacterial bioaugmentation for improving methane and hydrogen production from microalgae. Biotechnol Biofuels. 2013;6(1):92.

25. Van Soest PJ, Wine RH. Use of detergents in the analysis of fibrous feeds. IV. Determination of plant call-wall constituents. J Assoc Off Anal Chem. 1967;50:50-5.

26. Parnaudeau V, Nicolardot B, Pages J. Relevance of organic matter fractions as predictors of wastewater sludge mineralization in soil. J Environ Qual. 2004;33(5):1885-94

27. Cateto C, Hu G, Ragauskas A. Enzymatic hydrolysis of organosolv Kanlow switchgrass and its impact on cellulose crystallinity and degree of polymerization. Energy Environ Sci. 2011;4(4):1516-21.

28. Donohoe BS, Decker SR, Tucker MP, Himmel ME, Vinzant TB. Visualizing lignin coalescence and migration through maize cell walls following thermochemical pretreatment. Biotechnol Bioeng. 2008;101(5):913-25.

29. Johansson LS, Campbell J. Reproducible XPS on biopolymers: cellulose studies. Surf Interface Anal. 2004;36(8):1018-22.

30. Hu ZH, Liu SY, Yue ZB, Yan LF, Yang MT, Yu HQ. Microscale analysis of in vitro anaerobic degradation of lignocellulosic wastes by rumen microorganisms. Environ Sci Technol. 2008;42(1):276-81.

31. Ciolacu D, Pitol-Filho L, Ciolacu F. Studies concerning the accessibility of different allomorphic forms of cellulose. Cellulose. 2012;19(1):55-68.

32. Cagnon B, Py X, Guillot A, Stoeckli F, Chambat G. Contributions of hemicellulose, cellulose and lignin to the mass and the porous properties of chars and steam activated carbons from various lignocellulosic precursors. Bioresour Technol. 2009;100(1):292-8.

33. Bakker R, Elbersen H, Poppens R, Lesschen JP. Rice straw and wheat strawpotential feedstocks for the biobased economy. Utrecht: NL Agency; 2013.

34. Adotey B. Mathematical modeling of Clostridium thermocellum's metabolic responses to environmental perturbation. Lexington: University of Kentucky; 2011.

35. Sèbe G, Ham-Pichavant F, Ibarboure E, Koffi ALC, Tingaut P. Supramolecular structure characterization of cellulose II nanowhiskers produced by acid hydrolysis of cellulose I substrates. Biomacromolecules. 2012:13(2):570-8.

36. Hamzah F, Idris A, Shuan TK. Preliminary study on enzymatic hydrolysis of treated oil palm (Elaeis) empty fruit bunches fibre (EFB) by using combination of cellulase and $\beta 1-4$ glucosidase. Biomass Bioenergy. 2011;35(3):1055-9.

37. Elumalai S, Pan XJ. Chemistry and reactions of forest biomass in biorefining. In: Zhu J, Zhang X, Pan X, editors. Sustainable production of fuels, chemicals, and fibers from forest biomass, vol. 1067. Washington: American Chemical Society; 2011. p. 109-44.

38. Chang VS, Holtzapple MT. Fundamental factors affecting biomass enzymatic reactivity. Appl Biochem Biotechnol. 2000;84(1):5-37.

39. US-DOE. Biomass program: theoretical ethanol yield calculator and biomass feedstock composition and property database; 2016.

40. Badger P. Ethanol from cellulose: a general review. Trends New Crops New Uses. 2002;14:17-21.

41. Gírio FM, Fonseca C, Carvalheiro F, Duarte LC, Marques S, BogelLukasik R. Hemicelluloses for fuel ethanol: a review. Bioresour Technol. 2010;101(13):4775-800.

42. Gold ND, Martin VJJ. Global view of the Clostridium thermocellum cellulosome revealed by quantitative proteomic analysis. J Bacteriol. 2007;189(19):6787-95.

43. Stevenson DM, Weimer PJ. Expression of 17 genes in Clostridium thermocellum ATCC 27405 during fermentation of cellulose or cellobiose in continuous culture. Appl Environ Microbiol. 2005;71(8):4672-8.

44. Riederer A, Takasuka TE, Makino S-i, Stevenson DM, Bukhman YV, Elsen NL, Fox BG. Global gene expression patterns in Clostridium thermocellum as determined by microarray analysis of chemostat cultures on cellulose or cellobiose. Appl Environ Microbiol. 2011;77(4):1243-53.

45. Zhang Y-HP, Lynd LR. Cellulose utilization by Clostridium thermocellum: bioenergetics and hydrolysis product assimilation. In: Proceedings of the National Academy of Sciences of the United States of America. 2005; 102(20): 7321-7325.

46. Carlsson DO, Lindh J, Strømme M, Mihranyan A. Susceptibility of $I_{a^{-}}$and $I_{\beta}$-dominated cellulose to TEMPO-mediated oxidation. Biomacromolecules. 2015;16(5):1643-9. 
47. Ellis LD, Holwerda EK, Hogsett D, Rogers S, Shao X, Tschaplinski T, Thorne P, Lynd LR. Closing the carbon balance for fermentation by Clostridium thermocellum (ATCC 27405). Bioresour Technol. 2012;103(1):293-9.

48. Desvaux M, Guedon E, Petitdemange H. Carbon flux distribution and kinetics of cellulose fermentation in steady-state continuous cultures of Clostridium cellulolyticum on a chemically defined medium. J Bacteriol. 2001;183(1):119-30.

49. Desvaux M, Guedon E, Petitdemange H. Kinetics and metabolism of cellulose degradation at high substrate concentrations in steady-state continuous cultures of Clostridium cellulolyticum on a chemically defined medium. Appl Environ Microbiol. 2001;67(9):3837-45.

50. Zhu X, Cui J, Feng Y, Fa Y, Zhang J, Cui Q. Metabolic adaption of ethanoltolerant Clostridium thermocellum. PLoS ONE. 2013;8(7):e70631.

51. Raman B, Pan C, Hurst GB, Rodriguez M Jr, McKeown CK, Lankford PK, Samatova NF, Mielenz JR. Impact of pretreated switchgrass and biomass carbohydrates on Clostridium thermocellum ATCC 27405 cellulosome composition: a quantitative proteomic analysis. PLoS ONE. 2009:4(4):e5271.
52. Raman B, McKeown CK, Rodriguez M, Brown SD, Mielenz JR. Transcriptomic analysis of Clostridium thermocellum ATCC 27405 cellulose fermentation. BMC Microbiol. 2011;11(1):134.

53. Nataf Y, Bahari L, Kahel-Raifer H, Borovok I, Lamed R, Bayer EA, Sonenshein AL, Shoham Y. Clostridium thermocellum cellulosomal genes are regulated by extracytoplasmic polysaccharides via alternative sigma factors. Proc Natl Acad Sci. 2010;107(43):18646-51.

54. Yang S, Giannone RJ, Dice L, Yang ZK, Engle NL, Tschaplinski TJ, Hettich RL, Brown SD. Clostridium thermocellum ATCC27405 transcriptomic, metabolomic and proteomic profiles after ethanol stress. BMC Genomics. 2012;13(1):336

55. Lee WS, Chua ASM, Yeoh HK, Ngoh GC. A review of the production and applications of waste-derived volatile fatty acids. Chem Eng J. 2014;235:83-99.

56. Liu Y, Lü F, Shao L, He P. Alcohol-to-acid ratio and substrate concentration affect product structure in chain elongation reactions initiated by unacclimatized inoculum. Bioresour Technol. 2016;218:1140-50.

\section{Submit your next manuscript to BioMed Central and we will help you at every step:}

- We accept pre-submission inquiries

- Our selector tool helps you to find the most relevant journal

- We provide round the clock customer support

- Convenient online submission

- Thorough peer review

- Inclusion in PubMed and all major indexing services

- Maximum visibility for your research

Submit your manuscript at www.biomedcentral com/submit 